\title{
Investigation on combined copy number variation sequencing and cytogenetic karyotyping for prenatal diagnosis
}

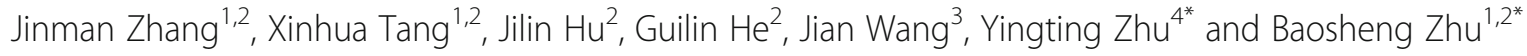

\begin{abstract}
Background: We aimed to evaluate the clinical value of copy number variation-sequencing (CNV-Seq) in combination with cytogenetic karyotyping in prenatal diagnosis.

Methods: CNV-Seq and cytogenetic karyotyping were performed in parallel for 9452 prenatal samples for comparison of the diagnostic performance of the two methods, and to evaluate the screening performance of maternal age, maternal serum screening, fetal ultrasound scanning and noninvasive prenatal testing (NIPT) for fetal pathogenic copy number variation (CNV).

Results: Among the 9452 prenatal samples, traditional karyotyping detected 704 cases (7.5\%) of abnormal cytogenetic karyotypes, 171 (1.8\%) chromosome polymorphism, 20 (0.2\%) subtle structural variations, 74 (0.7\%) mutual translocation (possibly balanced), 52 (0.6\%) without karyotyping results, and 8431 (89.2\%) normal cytogenetic karyotypes. Among the 8705 cases with normal karyotype, polymorphism, mutual translocation, or marker chromosome, CNV-Seq detected 63 cases (0.7\%) of pathogenic chromosome microdeletion/duplication. Retrospectively, noninvasive prenatal testing (NIPT) had high sensitivity and specificity for the screening of fetal pathogenic CNV, and NIPT combining with maternal age, maternal serum screening or fetal ultrasound scanning, which improved the screening performance.

Conclusion: The combined application of cytogenetic karyotyping and CNV-Seq significantly improved the detection rate of fetal pathogenic chromosome microdeletion/duplication. NIPT was recommended for the screening of pathogenic chromosome microdeletion/duplication, and NIPT combining with other screening methods further improved the screening performance for pathogenic fetal CNV.
\end{abstract}

Keywords: High-throughput sequencing, copy number variation, Prenatal diagnosis, Noninvasive prenatal testing, Chromosomal diseases

\footnotetext{
* Correspondence: bszhu@kmust.edu.cn; yzhu@tissuetechinc.com

${ }^{4}$ Research and Development Department, TissueTech, Inc., 7235 Corporate Center Drive, Suite B, Miami, Florida 33126, USA

${ }^{1}$ Faculty of Environmental Science and Engineering, Kunming University of

Science and Technology, Kunming, Yunnan 650500, People's Republic of

China

Full list of author information is available at the end of the article
}

(c) The Author(s). 2021 Open Access This article is licensed under a Creative Commons Attribution 4.0 International License, which permits use, sharing, adaptation, distribution and reproduction in any medium or format, as long as you give appropriate credit to the original author(s) and the source, provide a link to the Creative Commons licence, and indicate if changes were made. The images or other third party material in this article are included in the article's Creative Commons licence, unless indicated otherwise in a credit line to the material. If material is not included in the article's Creative Commons licence and your intended use is not permitted by statutory regulation or exceeds the permitted use, you will need to obtain permission directly from the copyright holder. To view a copy of this licence, visit http://creativecommons.org/licenses/by/4.0/. The Creative Commons Public Domain Dedication waiver (http://creativecommons.org/publicdomain/zero/1.0/) applies to the data made available in this article, unless otherwise stated in a credit line to the data. 


\section{Background}

Different levels and types of genetic variation exist in the human genome, ranging from single nucleotide mutations to structural or numerical chromosome abnormalities. One or more genetic variations may exist in an individual, and some genetic variations cause severe congenital malformations or death. In addition to triploid and numerical chromosome abnormalities, pathogenic chromosome microdeletion/duplication also leads to poor fetal prognosis. For example, Wolf-Hirschhorn syndrome mostly results in developmental retardation, unusual faces and structural abnormalities, and MillerDieker syndrome can be complicated by pachygyria; 22q11.21 microdeletion syndrome often has various degrees of cardiac malformations [1-6]. If pathogenic chromosome microdeletion/duplication can be diagnosed prenatally, the births of children with such severe congenital defects can be avoided.

However, the target diseases of traditional maternal serum screening are limited to common aneuploidies. Fetal ultrasound scanning is mainly used to monitor fetal growth and development, and to find structural fetal abnormalities and soft markers. Noninvasive prenatal testing (NIPT) using maternal plasma cell-free fetal DNA has made prenatal screening for pathogenic chromosome microdeletion/ duplication possible.

Traditional cytogenetic karyotyping has been used as the gold standard diagnosis of chromosome abnormalities for decades. However, it is time-consuming and labor-intensive, largely dependent on cell culture, and has a low chromosome resolution of $5 \sim 10 \mathrm{Mb}$. In recent years, the application of high-resolution chromosome micro-array analysis (CMA), which can detect abnormal chromosome number, micro-deletions/duplication, uniparental disomy, has revolutionized the testing methodology of prenatal diagnosis. It has been suggested in some studies that CMA can be solely used instead of cytogenetic karyotyping in prenatal diagnosis laboratories with limited human resources [7]. Nextgeneration sequencing (NGS) now offers an alternative methodology to CMA, named copy number variation sequencing (CNV-Seq) with a resolution of $0.2 \mathrm{Mb}$ for the detection of clinically significant chromosomal abnormalities. CNV-Seq has uniform sequencing coverage and relatively low price and has been gradually used in prenatal diagnosis [8]. However, more studies are required to further verify the efficiency of CNV-Seq in prenatal diagnosis.

Traditional karyotyping has characteristics of low-cost and covering the whole genome, including abnormal chromosome number and structural variation of specific regions, such as euchromatic and heterochromosomal regions. It highly depends on the experience of technicians to recognize these regions using different banding techniques under the microscope, which provide information about the frequency and location of these variations. Due to the morphologic similarity between chromosomes, karyotyping is difficult to accurately distinguish subtle structural variations. Genome copy number variation $(\mathrm{CNVs})$ refers to structural variations of DNA sequence of more than $0.2 \mathrm{Mb}$. Karyotyping by conventional chromosome banding technology cannot distinguish these subtle variations. Compared with karyotyping, CNV-Seq which based on next-generation sequencing technology and comparative genomics has high resolution, high throughput, and simple laboratory operations. However, CNV-Seq also has limitations such as short read lengths and not covering the whole genome, and it cannot detect balanced translocations, polymorphism, marker chromosomes, and other genetic variations out of the detection range, and it cannot accurately detect polyploidy and low-proportion chromosome mosaic. Karyotyping and CNV-Seq are two different technologies, and the combination of them in prenatal diagnosis may make up for each other's shortcomings and verifie each other's results to improve the accuracy of prenatal diagnosis. Therefore, in this study, we comparatively analyzed the difference between cytogenetic karyotyping and CNV-Seq for the same fetal samples, evaluated the value of adding CNV-Seq in traditional prenatal diagnosis, analyzed the performances of maternal age, maternal serum screening, NIPT and fetal ultrasound scanning for the screening of pathogenic fetal $\mathrm{CNV}$ and investigated whether combined application of these prenatal screening methods could improve the sensitivity and specificity for fetal pathogenic CNV.

\section{Methods Study patients}

All methods were carried out in accordance with relevant guidelines and regulations. The proposal of this study had been approved by the Ethics Committee of Institutional Research Board (IRB), First People's Hospital of Yunnan Province before this study was conducted. The study patients were 9452 singleton pregnant women who received invasive prenatal diagnosis after informed consent forms were signed, including allowance of data management and consent for manuscript publication, in the First People's Hospital of Yunnan Province, China, from January 2018 to December 2019. Among the study patients, 3582 (37.9\%) women were served by our hospital for their prenatal care, and 5870 (62.1\%) were transferred from the other hospitals because we are the provincial prenatal diagnosis center. The maternal age calculated by the expected date of confinement was 31 (27-36) years. The gestational age at prenatal diagnosis was 20 (19-21) weeks. Invasive prenatal diagnosis 
consisted of 8855 amniocentesis (93.7\%), 552 cordocentesis $(5.8 \%)$ and 44 chorion villus sampling $(0.5 \%)$.

\section{Prenatal screening}

Four types of prenatal screenings were involved in this study: (1) combined screening in $11 \sim 13^{+6}$ weeks that comprised of fetal NT measurement + maternal serum screening using pregnancy associated plasma protein-A (PAPP-A), placental growth factor (PLGF) and free human chorionic gonadotropin beta unit ( $\mathrm{f} \beta-\mathrm{HCG})$, with or without NIPT; (2) maternal serum screening in $16 \sim$ $20^{+6}$ weeks using alpha fetoprotein (AFP), $\mathrm{f} \beta$ - HCG and unconjugated estriol $\left(\mathrm{uE}_{3}\right)$, with or without NIPT; (3) NIPT only if gestational weeks at screening $\geq 21$ weeks, and (4) all study patients had fetal ultrasound scanning in our department. The cases with high risk of Down Syndrome (DS), high risk of Edwards Syndrome (ES), or high risk of both by maternal serum screening were all classified as high-risk cases. Fetal ultrasound scanning was classified into five grades based on the severity of abnormalities: grade 0: without abnormal findings; grade 1: fetuses with subtly ultrasound abnormalities other than grade 2, e.g. gallbladder was not detected; grade 2: soft markers that were closely associated with chromosome aneuploidy, such as thickened nuchal fold (NF), nuchal translucency (NT) $\geq 3.0 \mathrm{~mm}$, absence and/or dysplasia of nasal bone, mild to moderate ventriculomegaly, aberrant subclavian arteries, fetal growth restriction (FGR), short limb bones length, micrognathia, and acromphalus; grade 3: mild to moderate structural fetal malformations; grade 4: severe structural fetal malformations or lethal abnormalities. Maternal age $\geq 35$ years at the expected date of confinement was defined as advanced maternal age.

\section{Invasive prenatal diagnosis}

Three types of surgeries for invasive prenatal diagnosis were used in this study. Amniocentesis: Twenty $\mathrm{mL}$ of amniotic fluid was collected by aspiration for cell culture and cytogenetic karyotyping, and $5 \mathrm{~mL}$ for CNV-Seq. If amniotic fluid was contaminated by maternal blood, adherent amniocytes after cell culture were used for CNVSeq. Cordocentesis: Five $\mathrm{mL}$ of amniotic fluid was collected at first for CNV-Seq, and then $1.5 \mathrm{~mL}$ of cord blood for cell culture and cytogenetic karyotyping, and $0.5 \mathrm{~mL}$ of cord blood for hemoglobin electrophoresis to exclude maternal blood contamination. In prenatal diagnosis, the standard method to exclude maternal blood contamination should be linkage analysis of DNA polymorphism. We had used the method of STR polymorphism linkage analysis. In recent years, we used hemoglobin electrophoresis instead because STR polymorphism linkage analysis was much more timeconsuming and labor-intensive. Chorion villus sampling: a small amount of villous tissue was sampled for CNVSeq directly. Before 2019, we were inexperienced in villus cell culture techniques. Therefore, the cases received chorion villus sampling were those with severe fetal structural abnormalities. No villus cell culture was applied for those cases, and only CNVs was provided.

\section{Laboratory testing \\ Cell culture and cytogenetic karyotyping}

Amniotic fluid and umbilical blood samples were set up for cell culture following the standard protocols. Chromosome preparations were G-banded using trypsin-Giemsa staining for cytogenetic karyotyping after a series of standard protocols including colchicine treatment, hypotonic treatment, fixation and centrifugation. Karyotypes were diagnosed according to the international system for human cytogenetic nomenclature (ISCN, 2009) [9, 10]. The classification and abbreviations of abnormal karyotypes in this study were as follow: DS, ES, Patau syndrome (PS), super female syndrome (XXX), super male syndrome (XYY), Klinefelter syndrome (XXY), Turner syndrome (Turner), abnormal sex chromosome number mosaic (Sex A Mosaic), autosomal aneuploid mosaic (Auto A Mosaic), possibly balanced mutual translocation (Translocation), chromosome polymorphism (Polymorphism), triploid, chromosome fragment duplication/deletion, subtle structural variations such as inv. (21), inv. (4), dup (21), inv. (Y), inv. (1), inv. (5), inv. (12), inv. (8), inv. (19), inv. (Y), inv. (10), inv. (16). A total of 52 cases had only CNV-Seq results, but no karyotyping results. Among them, 44 cases who received chorion villus sampling, since our center cannot provide villus cell culture during that time; 8 cases encountered amniotic fluid cell culture failure. The maximum and minimum gestational weeks of amniotic fluid cell culture failure were 31 and 20 weeks, respectively. It should be noted that none of the 52 cases with missing results were used in the data analysis of this study.

\section{CNV-Seq and result interpretation}

Nextseq 550AR platform (Illumina, San Diego, CA) was used for DNA sequencing, with an average sequencing depth of $0.08 \times$, following the Q30 sequencing quality standard. The amount of fetal DNA used for CNV-Seq was $10 \sim 50 \mathrm{ng}$ for each prenatal sample. AnnoroadPD software (Annoroad Gene Technology Co., Ltd., Beijing, China) was applied to analyze the sequencing data referring to the human reference genome GRCh37/hg19. The identified fetal CNV were interpreted [11] and classified into five categories: pathogenic (P-), likely pathogenic (LP-), uncertain significance (VUS-), likely benign (LB-) and benign (B-), according to the standards and guidelines that were jointly developed by the American College of Medical Genetics and Genomics (ACMG), the 
Association for Molecular Pathology (AMP) and the College of American Pathologists (CAP) in 2015. To conveniently show the CNV-Seq results, we used "P"as abbreviation for pathogenic chromosome microdeletion/duplication, "None" for no copy number variation found, "auto A" for autosomal aneuploidy, "sex A" for abnormal sex chromosomes number, "auto AM" for autosomal aneuploidy mosaic, and "sex AM" for abnormal sex chromosomes number mosaic. Cytogenetic karyotyping was the diagnostic method for numerical and structural chromosome abnormalities, and high-throughput sequencing for CNV. For LPand VUS-, family (parents and fetuses) CNV-Seq tests, fluorescence in-situ hybridization (FISH) or multiplex ligation probe amplification (MLPA) were used for further verification.

\section{Statistical analysis}

The data were analyzed statistically using IBM SPSS Statistics (version 22.0, IBM Corp., Armonk, NY, USA). Continuous variables (for example, age and gestational weeks at prenatal diagnosis) were expressed as "median [lower quartile, upper quartile]", and analyzed using Kruskal-Wallis one-way analysis of variance. Categorical variables are represented by "n (\%)" and analyzed using Chi-square test for two-way disordered $\mathrm{R} \times \mathrm{C}$ table. Calculation for sensitivity and specificity: sensitivity $=$ true positive / (true positive + false negative) " $100 \%$; specificity = true negative / (true negative + false positive) ${ }^{*} 100 \%$. Paired chi-square test was used to test the difference between CNV-Seq and various prenatal screening methods and prenatal diagnosis results $(P<0.01$ was considered statistically significant). Missing items were not applied in data analysis.

\section{Results}

\section{Basic characteristics of study patients}

Basic information of 9452 cases of prenatal diagnosis was listed and statistically analyzed in Table 1. Among study patients, $9452(100 \%)$ had received one to two times of fetal ultrasonography in our center, 5688 (60.2\%) had maternal serum screening, 1409 (14.9\%) had NIPT, $551(0.58 \%)$ had both NIPT and maternal serum screening, and 3142 cases (33.2\%) were in advanced maternal age. The results showed that only 1165 (12.3\%) of patients received invasive prenatal diagnosis due to high risk of NIPT. Other indications for prenatal diagnosis included advanced maternal age, abnormal fetal ultrasound scanning, high risk of maternal serum screening, adverse reproductive history, family history of singlegene genetic diseases, or others.

\section{Comparison of results between CNV-Seq and cytogenetic} karyotyping

The results of 9452 cases of cytogenetic karyotyping were listed in Table 2: a total of 704 (7.5\%) cases of fetal chromosome abnormalities, 171 (1.8\%) chromosomal polymorphism, $20(0.2 \%)$ subtle structural variations, 74 $(0.7 \%)$ mutual translocation (possibly balanced), 52 (0.6\%) without karyotyping results, and 8431 (89.2\%) normal karyotypes were detected.

The results of CNV-Seq in Tables 2, 8,354 fetuses with $\mathrm{CNV}$-Seq findings were included as None, B-, and LB-, cytogenetic karyotyping showed that except for 2 cases of triploid, the rest 271 cases of abnormal karyotypes had good prognosis. A total of 530 cases of fetal aneuploidies (DS, ES, PS, XXY, XYY) were diagnosed, and the results of karyotyping and $\mathrm{CNV}$-Seq were consistent. The details for 60 cases of pathogenic microdeletion/duplication detected by CNV-Seq were shown in Table 3 . CNV-Seq detected 1 case of chromosomal aneuploidy and 2 cases of mosaic in fetuses with normal cytogenetic karyotypes. Furthermore, 2 cases (No.29 and 30) of pathogenic microdeletion/duplication were detected in 9 fetuses with marker chromosomes, and 1 case (No.38) of pathogenic microdeletion/duplication were detected in fetuses with mutual translocations (Seen in Table 4). Therefore, we may conclude that the combination of the two methodologies significantly improved the accuracy of prenatal diagnosis for fetal pathogenic $\mathrm{CNV}$ and was helpful to assess fetal prognosis. Due to its detection limitations, for example, two cases of triploid by karyotyping had normal CNV-Seq results, CNV-Seq could not replace karyotyping at present stage but might be an effective complement.

Performances of maternal age, maternal serum screening, NIPT and fetal ultrasound scanning for pathogenic CNVSeq results and pathogenic karyotypes

The target diseases of maternal serum screening are common chromosomal aneuploidies. For fetuses with pathogenic microdeletion/duplication, the prognosis is mostly poor. NIPT is the ideal prenatal screening method for pathogenic microdeletion/duplication, but the cost may limit its clinical use to a certain extent. If NIPT was unavailable, we wondered whether other screening methods could recognize pathogenic microdeletion/duplication. In this study, we retrospectively analyzed the results of maternal age, maternal serum screening, NIPT, and fetal ultrasound scanning for women with pathogenic fetal CNV-Seq results, including pathogenic microdeletion/duplication and Auto A, Sex A, Auto AM, Sex AM, as shown in Table 5. NIPT missed one case of Auto AM (CNV-Seq) and Triploid (karyotypes), shown in Table 6. In maternal serum screening, $55.2 \%$ of pathogenic microdeletion/ 
Table 1 Characteristics of study population

\begin{tabular}{|c|c|}
\hline Characteristic & Study population $(n=9452)$ \\
\hline Maternal age (years) & $31(27-36)$ \\
\hline Advanced maternal age ( $\geq 35 \mathrm{yrs}$ ) & $3142(33.2)$ \\
\hline \multicolumn{2}{|l|}{ Nation } \\
\hline Han & $6593(69.8)$ \\
\hline Yi & $822(8.7)$ \\
\hline Bai & $433(4.6)$ \\
\hline Dai & $282(3.0)$ \\
\hline Hui & $250(2.6)$ \\
\hline Zhuang & $167(1.8)$ \\
\hline Naxi & $145(1.5)$ \\
\hline Hani & $112(1.2)$ \\
\hline Others & $648(6.8)$ \\
\hline \multicolumn{2}{|l|}{ Parity } \\
\hline Nulliparous & $3457(36.6)$ \\
\hline Parous & $5995(63.4)$ \\
\hline$=1$ & $5355(56.7)$ \\
\hline$=2$ & $567(6.0)$ \\
\hline$\geq 3$ & $64(0.7)$ \\
\hline Gestational age at invasive diagnosis (weeks) & $20(19-21)$ \\
\hline \multicolumn{2}{|l|}{ Invasive prenatal diagnosis procedure } \\
\hline Amniocentesis & $8855(93.7)$ \\
\hline Cordocentesis & $552(5.8)$ \\
\hline Chorion villus sampling & $44(0.5)$ \\
\hline Maternal or/and paternal chromosome abnormalities & $155(1.6)$ \\
\hline History of bearing child with chromosome abnormalities & $203(2.1)$ \\
\hline \multicolumn{2}{|l|}{ Indications for invasive prenatal diagnosis } \\
\hline NIPT high-risk & $415(4.4)$ \\
\hline Maternal serum screening high-risk & $1984(21.0)$ \\
\hline DS high-risk & $2999(31.7)$ \\
\hline ES high-risk & $799(8.5)$ \\
\hline \multicolumn{2}{|l|}{ Both DS and ES high-risk } \\
\hline Advanced maternal age ( $\geq 35 \mathrm{yrs}$ ) & $1177(12.5)$ \\
\hline Abnormal fetal ultrasonography & $1229(13.0)$ \\
\hline Grade 1 & $1857(19.6)$ \\
\hline Grade 2 & $1549(16.4)$ \\
\hline Grade 3 & $531(5.6)$ \\
\hline Grade 4 & $219(2.3)$ \\
\hline Other indications & $831(8.8)$ \\
\hline$\geq$ two indications & $3816(40.4)$ \\
\hline
\end{tabular}

duplication (CNV-Seq) and $42.1 \%$ of unbalanced fragment deletion/duplication (karyotypes) showed high risks results. As to abnormal ultrasound findings (grades 2-4), there was significant difference between CNV-Seq of auto $\mathrm{A}$ and pathogenic microdeletion/ duplication
(73.6\% versus $43.2 \%, P<0.001$ ). Regarding to pathogenic karyotypes, NIPT missed one case of triploid, whose maternal serum screening and fetal ultrasound were abnormal. Only $42.2 \%$ of severe chromosomal abnormalities (aneuploidy, unbalanced fragment deletion/ 
Table 2 Comparison of results between cytogenetic karyotyping and CNV-Seq

\begin{tabular}{|c|c|c|c|c|c|c|c|c|c|c|c|c|}
\hline \multirow{2}{*}{$\begin{array}{l}\text { cytogenetic } \\
\text { karyotyping }\end{array}$} & \multirow[b]{2}{*}{$\begin{array}{l}\text { None } \\
(n=4851)\end{array}$} & \multicolumn{10}{|l|}{ CNV } & \multirow[t]{2}{*}{$P$ value } \\
\hline & & $\begin{array}{l}\mathrm{B} \\
(n= \\
38) \\
\end{array}$ & $\begin{array}{l}\text { LB }(n= \\
3465)\end{array}$ & $\begin{array}{l}\text { VUS } \\
(n= \\
304)\end{array}$ & $\begin{array}{l}\text { LP } \\
(n= \\
23) \\
\end{array}$ & $\begin{array}{l}\text { P-del/dup } \\
(n=118)\end{array}$ & $\begin{array}{l}\text { Auto A } \\
(n=446)\end{array}$ & $\begin{array}{l}\text { Auto A M } \\
(n=18)\end{array}$ & $\begin{array}{l}\text { Sex A } \\
(n=156)\end{array}$ & $\begin{array}{l}\text { Sex A M } \\
(n=33)\end{array}$ & $\begin{array}{l}\text { Total } \\
(n= \\
9452)\end{array}$ & \\
\hline Normal & $\begin{array}{l}4666 \\
(96.2)\end{array}$ & $\begin{array}{l}36 \\
(94.7)\end{array}$ & $\begin{array}{l}3355 \\
(96.8)\end{array}$ & $\begin{array}{l}289 \\
(95.1)\end{array}$ & $\begin{array}{l}22 \\
(95.7)\end{array}$ & $60(50.8)$ & $0(0.0)$ & $1(5.6)$ & $1(0.6)$ & $1(3.0)$ & $\begin{array}{l}8431 \\
(89.2)\end{array}$ & $<0.001$ \\
\hline DS & $0(0.0)$ & $\begin{array}{l}0 \\
(0.0)\end{array}$ & $0(0.0)$ & $0(0.0)$ & $\begin{array}{l}0 \\
(0.0)\end{array}$ & $0(0.0)$ & $358(80.3)$ & $0(0.0)$ & $0(0.0)$ & $0(0.0)$ & $358(3.8)$ & \\
\hline ES & $0(0.0)$ & $\begin{array}{l}0 \\
(0.0)\end{array}$ & $0(0.0)$ & $0(0.0)$ & $\begin{array}{l}0 \\
(0.0)\end{array}$ & $0(0.0)$ & $55(12.3)$ & $0(0.0)$ & $0(0.0)$ & $0(0.0)$ & $55(0.6)$ & \\
\hline PS & $0(0.0)$ & $\begin{array}{l}0 \\
(0.0)\end{array}$ & $0(0.0)$ & $0(0.0)$ & $\begin{array}{l}0 \\
(0.0)\end{array}$ & $0(0.0)$ & $12(2.7)$ & $0(0.0)$ & $0(0.0)$ & $0(0.0)$ & $12(0.1)$ & \\
\hline$X X X$ & $0(0.0)$ & $\begin{array}{l}0 \\
(0.0)\end{array}$ & $0(0.0)$ & $0(0.0)$ & $\begin{array}{l}0 \\
(0.0)\end{array}$ & $0(0.0)$ & $0(0.0)$ & $0(0.0)$ & $27(17.3)$ & $1(3.0)$ & $28(0.3)$ & \\
\hline$X Y Y$ & $0(0.0)$ & $\begin{array}{l}0 \\
(0.0)\end{array}$ & $0(0.0)$ & $0(0.0)$ & $\begin{array}{l}0 \\
(0.0)\end{array}$ & $0(0.0)$ & $0(0.0)$ & $0(0.0)$ & $33(21.2)$ & $0(0.0)$ & $33(0.3)$ & \\
\hline$X X Y$ & $0(0.0)$ & $\begin{array}{l}0 \\
(0.0)\end{array}$ & $0(0.0)$ & $0(0.0)$ & $\begin{array}{l}0 \\
(0.0)\end{array}$ & $0(0.0)$ & $0(0.0)$ & $0(0.0)$ & $72(46.2)$ & $0(0.0)$ & $72(0.8)$ & \\
\hline mark & $2(0.0)$ & $\begin{array}{l}1 \\
(2.6)\end{array}$ & $2(0.1)$ & $2(0.7)$ & $\begin{array}{l}0 \\
(0.0)\end{array}$ & $2(1.7)$ & $0(0.0)$ & $0(0.0)$ & $0(0.0)$ & $0(0.0)$ & $9(0.1)$ & \\
\hline Turner & $0(0.0)$ & $\begin{array}{l}0 \\
(0.0)\end{array}$ & $0(0.0)$ & $0(0.0)$ & $\begin{array}{l}0 \\
(0.0)\end{array}$ & $0(0.0)$ & $0(0.0)$ & $0(0.0)$ & $11(7.1)$ & $2(6.1)$ & $13(0.1)$ & \\
\hline Sex A Mosaic & $4(0.1)$ & $\begin{array}{l}0 \\
(0.0)\end{array}$ & $4(0.1)$ & $1(0.3)$ & $\begin{array}{l}0 \\
(0.0)\end{array}$ & $2(1.7)$ & $0(0.0)$ & $0(0.0)$ & $3(1.9)$ & $28(84.8)$ & $42(0.4)$ & \\
\hline $\begin{array}{l}\text { Auto A } \\
\text { Mosaic }\end{array}$ & $2(0.0)$ & $\begin{array}{l}0 \\
(0.0)\end{array}$ & $1(0.0)$ & $0(0.0)$ & $\begin{array}{l}0 \\
(0.0)\end{array}$ & $0(0.0)$ & $2(0.4)$ & $16(88.9)$ & $0(0.0)$ & $0(0.0)$ & $21(0.2)$ & \\
\hline Translocation & $47(1.0)$ & $\begin{array}{l}0 \\
(0.0)\end{array}$ & $23(0.7)$ & $3(1.0)$ & $\begin{array}{l}0 \\
(0.0)\end{array}$ & $1(0.8)$ & $0(0.0)$ & $0(0.0)$ & $0(0.0)$ & $0(0.0)$ & $74(0.8)$ & \\
\hline Polymorphism & $102(2.1)$ & $\begin{array}{l}0 \\
(0.0)\end{array}$ & $63(1.8)$ & $5(1.6)$ & $\begin{array}{l}0 \\
(0.0)\end{array}$ & $0(0.0)$ & $0(0.0)$ & $1(5.6)$ & $0(0.0)$ & $0(0.0)$ & $171(1.8)$ & \\
\hline Triploid & $2(0.0)$ & $\begin{array}{l}0 \\
(0.0)\end{array}$ & $0(0.0)$ & $0(0.0)$ & $\begin{array}{l}0 \\
(0.0)\end{array}$ & $0(0.0)$ & $0(0.0)$ & $0(0.0)$ & $0(0.0)$ & $0(0.0)$ & $2(0.0)$ & \\
\hline Unbalance & $0(0.0)$ & $\begin{array}{l}0 \\
(0.0)\end{array}$ & $0(0.0)$ & $2(0.7)$ & $\begin{array}{l}0 \\
(0.0)\end{array}$ & 49 (41.5) & $0(0.0)$ & $0(0.0)$ & $0(0.0)$ & $0(0.0)$ & $51(0.5)$ & \\
\hline No results \# & $14(0.3)$ & $\begin{array}{l}1 \\
(2.6)\end{array}$ & $9(0.3)$ & $2(0.7)$ & $\begin{array}{l}1 \\
(4.3)\end{array}$ & $2(1.7)$ & $18(4.0)$ & $0(0.0)$ & $5(3.2)$ & $0(0.0)$ & $52(0.6)$ & \\
\hline Sex and other & $0(0.0)$ & $\begin{array}{l}0 \\
(0.0)\end{array}$ & $0(0.0)$ & $0(0.0)$ & $\begin{array}{l}0 \\
(0.0)\end{array}$ & $2(1.7)$ & $1(0.2)$ & $0(0.0)$ & $4(2.6)$ & $1(3.0)$ & $8(0.1)$ & \\
\hline Others & $12(0.2)$ & $\begin{array}{l}0 \\
(0.0)\end{array}$ & $8(0.2)$ & $0(0.0)$ & $\begin{array}{l}0 \\
(0.0)\end{array}$ & $0(0.0)$ & $0(0.0)$ & $0(0.0)$ & $0(0.0)$ & $0(0.0)$ & $20(0.2)$ & \\
\hline
\end{tabular}

duplication, triploidy) were screened out by advanced maternal age. The detection rate of abnormal fetal ultrasound findings (grade 2-4) in fetuses with abnormal karyotypes were DS $69.9 \%$, ES $85.5 \%$, PS 91.7\%, unbalanced fragment deletion/duplication $56.8 \%$, triploid 100\%, XXX 14.3\%, XYY 24.2\%, and XXY 18.1\%. We speculated that there might be a dose-effect between fetal ultrasound abnormalities and chromosomal diseases, and a difference between autosomal and sex chromosomal abnormalities. Therefore, maternal age, maternal serum screening, fetal ultrasound scanning and NIPT all had certain predictive values for pathogenic CNV-Seq results and pathogenic karyotypes (chromosomal aneuploidy, unbalanced segment deletion/duplication, and triploid).

As seen in Table 7, for pathogenic fetal CNV-Seq results, NIPT had the highest sensitivity of 1.00 (0.99-1.00) but lowest specificity of 0.22 (0.18-0.26), while maternal serum screening had higher sensitivity of $0.63(0.57-0.68)$ and lower specificity of 0.37 (0.35-0.39). The sensitivity and specificity of fetal ultrasound scanning were $0.69(0.66-0.72)$ and 0.59 (0.57-0.60), respectively. Advanced maternal age had a specificity of $0.68(0.67-0.70)$ and a sensitivity of 0.39 (0.35-0.42). 
Table 3 Clinical data of 60 cases with normal karyotype but pathogenic microdeletion/duplication

\begin{tabular}{|c|c|c|c|c|}
\hline $\begin{array}{l}\text { Pathogenic microdeletion/ } \\
\text { duplication }\end{array}$ & (n) & $\begin{array}{l}\text { Termination of } \\
\text { pregnancy (n) }\end{array}$ & $\begin{array}{l}\text { Continued } \\
\text { pregnancy(n) }\end{array}$ & Pregnancy outcomes \\
\hline $\begin{array}{l}\text { Xp22.31 deletion } \\
\text { X-linked ichthyosis }\end{array}$ & 17 & 6 & 11 & $\begin{array}{l}3 \text { female fetuses, } 2 \text { of which continued pregnancy, and } 1 \text { of which terminated } \\
\text { due to severe type thalassaemia. } \\
14 \text { male fetuses, } 9 \text { of which continued pregnancy, and } 5 \text { of which terminated. }\end{array}$ \\
\hline $\begin{array}{l}\text { 22q11.21 deletion } \\
\text { Digeorge syndrome }\end{array}$ & 7 & 6 & 1 & $\begin{array}{l}\text { The pregnant women have mild mental retardation, fetus had right aortic } \\
\text { arch, maternal derived } 22 \text { q11.21 microdeletion, the couple chose to continue } \\
\text { pregnancy }\end{array}$ \\
\hline $\begin{array}{l}\text { Xp21.1 deletion } \\
\text { Duchenne muscular } \\
\text { dystrophy }\end{array}$ & 1 & 1 & 0 & Male fetus, the couple chose to terminate the pregnancy。 \\
\hline $\begin{array}{l}\text { Xp21.1 duplication } \\
\text { Duchenne muscular } \\
\text { dystrophy }\end{array}$ & 1 & 0 & 1 & Female fetus, the couple chose to continue the pregnancy。 \\
\hline $\begin{array}{l}\text { Other pathogenic autosomal } \\
\text { microdeletion/duplication }\end{array}$ & 34 & 30 & 4 & $\begin{array}{l}2 \text { cases of } 17 p 12 \text { deletion ( } 1 \text { case was maternal origin), } 1 \text { case of 1q21.1-q21.2 } \\
\text { deletion (maternal origin), 22q11.2 microduplication (paternal origin), the } \\
\text { couple chose to continue the pregnancy. }\end{array}$ \\
\hline Total & 60 & 44 & 16 & \\
\hline
\end{tabular}

\section{Correlation between fetal CNV-Seq and indications for prenatal diagnosis}

According to the number of indications for prenatal diagnosis, the 9452 women were divided into four groups: (1) single indication, (2) positivity for any two or (3) three or (4) four indications. Indications included high risk in NIPT, high risk in maternal serum screening, fetal ultrasound abnormalities (Grade 2-4), advanced maternal age, and other indications such as adverse childbearing history except monogenic diseases. The sensitivity and specificity of different prenatal diagnostic indications for the screening of pathogenic microdeletion/microduplication were lists in Table 8. Single indication had the highest sensitivity and the lowest specificity. In a similar trend, four indicators had the lowest sensitivity and the highest specificity. Accordingly, to achieve the optimal sensitivity and specificity, a prenatal screening program that combines two methods could be considered.

\section{Discussion}

Combination of cytogenetic karyotyping and CNV-Seq can prenatally diagnose more fetal pathogenic microdeletion/duplication and provide comprehensive prenatal information

In addition to traditional cytogenetic karyotyping, CMA and $\mathrm{CNV}$-Seq have gradually been used in prenatal diagnosis. CNV-Seq is worth applying in prenatal diagnosis due to its lower cost and uniform sequencing coverage. Fetuses with normal karyotype/chromosome polymorphism usually have good prognosis, but pathogenic microdeletion/duplication cannot be excluded. In this study, among fetuses with normal karyotypes, CNV-Seq diagnosed $60(0.6 \%)$ cases of pathogenic $\mathrm{CNV}$, and fortunately the births of 44 fetuses with poor prognosis were avoided. A complex case was also prenatal diagnosed with CNV-Seq result of 47,XXY and karyotyping result of 46,XX. SRY gene detection indicated a male gender, but all 6 loci on AZF gene were missing. Fetal ultrasound showed male external genitalia. Taking fetal ultrasound findings together, the fetus might have sexual reversal and risks of abnormal reproductive system development in puberty. The parents were fully informed the advantages, disadvantages and limitations of karyotyping and CNV-Seq, and to make clear that the two results cannot be denied by each other but be mutually complementary. The couple chose to continue the pregnancy. The boy is now 1.5 years old and is generally healthy. Follow-up and etiological examination were recommended. On the other hand, we should make clear that not all fetuses with structural chromosomal abnormalities by karyotyping have poor prognosis. For example, mutual translocation (paternal/maternal/de novo) with normal CNV-Seq and fetal ultrasound is very much likely that the fetuses have good prognosis. The combination of karyotyping and CNV-Seq enables mutual verification of the results in prenatal diagnosis and helps to avoid misdiagnosis and provide more information for comprehensive evaluation of fetal prognosis. However, the combined application of CNV-Seq and karyotyping may lead to increased economic burden. It needs further verification about whether the cost-effectiveness is worth promoting. We need to choose an appropriate prenatal diagnosis program based on our own characteristics.

\section{Combined several prenatal screening significantly improves the specificity but reduces the sensitivity for fetal pathogenic CNV}

Maternal serum screening detects $70 \sim 80 \%$ of DS, at a false positive rate of $5 \%$ [12]. It was reported that a small 
Table 4 Forty five cases with inconsistent karyotyping and CNV-seq results

\begin{tabular}{|c|c|c|c|c|c|}
\hline No. & $\begin{array}{l}\text { Indications for } \\
\text { prenatal diagnosis }\end{array}$ & $\begin{array}{l}\text { Abnormal } \\
\text { karyotypes }\end{array}$ & CNV-seq results & Fetal ultrasound & $\begin{array}{l}\text { Pregnancy } \\
\text { outcomes }\end{array}$ \\
\hline 1 & $\begin{array}{l}\text { Advanced maternal } \\
\text { age }\end{array}$ & $69, X X X$ & $46, X X$ & $\begin{array}{l}\text { Fetal growth restrction, tethered spinal cord, ankle } \\
\text { joint reflexion, diaphragm expansion }\end{array}$ & $\begin{array}{l}\text { Termination } \\
\text { of pregnancy }\end{array}$ \\
\hline 2 & $\begin{array}{l}\text { Maternal serum } \\
\text { screening ES high } \\
\text { risk、NIPT low-risk }\end{array}$ & $69, X X X$ & $46, X X$ & $\begin{array}{l}\text { Fetal trunk is significantly smaller than the head, left } \\
\text { lung absent, double Outlet Right Ventricle }\end{array}$ & $\begin{array}{l}\text { Termination } \\
\text { of pregnancy }\end{array}$ \\
\hline 3 & NIPT high-risk & $47, X X X$ & 46XX[20\%]/47XXX[80\%] & Normal & $\begin{array}{l}\text { Gave birth to } \\
\text { a girl }\end{array}$ \\
\hline 4 & NIPT high-risk & $\begin{array}{l}45, X[18] / 46, X \\
i(X)(p 10)[34]\end{array}$ & $\begin{array}{l}45, X, \text { del }(X p 11.21- \\
\text { p22.33)52.45mb(73\%)/46, } \\
\text { XX(27\%) }\end{array}$ & Thickened nuchal folder & $\begin{array}{l}\text { Continue } \\
\text { pregnancy }\end{array}$ \\
\hline 5 & NIPT high-risk & $45, x$ & $46, X X[11 \%] / 45, X[89 \%]$ & Fetal growth restrction & $\begin{array}{l}\text { Termination } \\
\text { of pregnancy }\end{array}$ \\
\hline 6 & NIPT high-risk & $\begin{array}{l}45, X[53] / 47, X X X \\
{[5]}\end{array}$ & $45, X$ & Ventricular septal defect & $\begin{array}{l}\text { Termination } \\
\text { of pregnancy }\end{array}$ \\
\hline 7 & $\begin{array}{l}\text { Advanced maternal } \\
\text { age }\end{array}$ & $\begin{array}{l}45, X[18] / 46, X \\
+\operatorname{mar}[24]\end{array}$ & $\begin{array}{l}45 X \text { with possible } X \text { structure } \\
\text { abnormality }\end{array}$ & $\begin{array}{l}\text { Mild bilateral renal hydrops, bilateral } \\
\text { ventriculomegaly, slightly larger right heart }\end{array}$ & $\begin{array}{l}\text { Termination } \\
\text { of pregnancy }\end{array}$ \\
\hline 8 & NIPT high-risk & $\begin{array}{l}45, X[19] / 46, X Y \\
{[16]}\end{array}$ & Turner mosaic & Bilateral renal pelvis separation & $\begin{array}{l}\text { Termination } \\
\text { of pregnancy }\end{array}$ \\
\hline 9 & NIPT high-risk & $45, X[35] / 46, X X[9]$ & $45, X$ & Normal & $\begin{array}{l}\text { Termination } \\
\text { of pregnancy }\end{array}$ \\
\hline 10 & $\begin{array}{l}\text { Maternal serum } \\
\text { screening high risk }\end{array}$ & $\begin{array}{l}47, X Y Y[7] / 46, \\
X Y[56]\end{array}$ & $\begin{array}{l}\text { Y chromosome } \\
\text { duplication(16.85 Mb) }\end{array}$ & Normal & $\begin{array}{l}\text { Gave birth to } \\
\text { a boy }\end{array}$ \\
\hline 11 & NIPT high-risk & $45, X[22] / 46, X Y[8]$ & $\begin{array}{l}\text { Yq11.221-q11.223 } \\
\text { deletion(VUS) }\end{array}$ & Bowel echo enhancement & $\begin{array}{l}\text { Termination } \\
\text { of pregnancy }\end{array}$ \\
\hline 12 & $\begin{array}{l}\text { Maternal serum } \\
\text { screening high risk }\end{array}$ & $45, X[37] / 46, X Y[7]$ & $\begin{array}{l}\text { 4p15.33、Yq11.222-q11.223 } \\
\text { deletion(VUS) }\end{array}$ & Normal & $\begin{array}{l}\text { Termination } \\
\text { of pregnancy }\end{array}$ \\
\hline 13 & $\begin{array}{l}\text { Childbearing history } \\
\text { of gastrodialysis }\end{array}$ & $\begin{array}{l}45, X[10] / 46 \\
X X[42]\end{array}$ & Likely benign variation & Left nasal bone dysplasia, right Nasal bone absent & $\begin{array}{l}\text { Gave birth to } \\
\text { a girl }\end{array}$ \\
\hline 14 & NIPT high-risk & $45 X[5] / 46 X X$ & Likely benign variation & Retract chin and lower lip & $\begin{array}{l}\text { Continue } \\
\text { pregnancy }\end{array}$ \\
\hline 15 & NIPT high-risk & $45, X[8] / 46, X X[92]$ & Likely benign variation & Normal & $\begin{array}{l}\text { Termination } \\
\text { of pregnancy }\end{array}$ \\
\hline 16 & NIPT high-risk & $45, X[4] / 46, X X[51]$ & Likely benign variation & Normal & $\begin{array}{l}\text { Continue } \\
\text { pregnancy }\end{array}$ \\
\hline 17 & $\begin{array}{l}\text { Couples are } \\
\text { thalassaemia carrier }\end{array}$ & $\begin{array}{l}45, X[10] / 46 \\
X Y[28]\end{array}$ & Normal & Normal & $\begin{array}{l}\text { Termination } \\
\text { of pregnancy }\end{array}$ \\
\hline 18 & $\begin{array}{l}\text { Advanced maternal } \\
\text { age }\end{array}$ & $\begin{array}{l}47, X X Y[10] 46, \\
X Y[45]\end{array}$ & Normal & $\begin{array}{l}\text { Bilateral renal pelvis separation, bowel echo } \\
\text { enhancement }\end{array}$ & $\begin{array}{l}\text { Gave birth to } \\
\text { a boy }\end{array}$ \\
\hline 19 & NIPT high-risk & $\begin{array}{l}45, X[34] / 47 \\
X X X[26]\end{array}$ & Normal & Bilateral renal pelvis separation & $\begin{array}{l}\text { Termination } \\
\text { of pregnancy }\end{array}$ \\
\hline 20 & $\begin{array}{l}\text { Couples are } \\
\text { thalassaemia carrier }\end{array}$ & $45, X[5] / 46, X Y[40]$ & Normal & The fetus is smaller 8 days than gestational week & $\begin{array}{l}\text { Gave birth to } \\
\text { a boy }\end{array}$ \\
\hline 21 & NIPT high-risk & $\begin{array}{l}47, X N,+21[18] / 46 \\
X N[31]\end{array}$ & $47, \mathrm{XN},+21[58 \%]$ & $\begin{array}{l}\text { Small humerus and femoral length, small head } \\
\text { circumference }\end{array}$ & $\begin{array}{l}\text { Termination } \\
\text { of pregnancy }\end{array}$ \\
\hline 23 & NIPT high-risk & $\begin{array}{l}47, X X,+21[27] / 46 \\
X X[8]\end{array}$ & DS & Normal & $\begin{array}{l}\text { Termination } \\
\text { of pregnancy }\end{array}$ \\
\hline 24 & NIPT high-risk & $\begin{array}{l}47, X X,+18[29] \\
/ 46, X X[5](G T G)\end{array}$ & $47, \mathrm{XN},+18[78 \%] / 46, \mathrm{XN}[22 \%]$ & $\begin{array}{l}\text { Incontinuity of lower part of cerebellar vermis, } \\
\text { complete endocardial cushion defect }\end{array}$ & $\begin{array}{l}\text { Termination } \\
\text { of pregnancy }\end{array}$ \\
\hline 25 & NIPT high-risk & $\begin{array}{l}47, X N,+15[4] / 46, \\
X N[51]\end{array}$ & Trisomy 15 mosaic (50\%) & Single umbilical artery & $\begin{array}{l}\text { Termination } \\
\text { of pregnancy }\end{array}$ \\
\hline 26 & NIPT high-risk & $\begin{array}{l}47, X Y,+5[15] / 46 \\
X Y[47]\end{array}$ & CNVs benign variation & $\begin{array}{l}\text { FGR, ventricular septal defect, thickened right } \\
\text { ventricular wall, Aorta straddle, enhanced echo of }\end{array}$ & $\begin{array}{l}\text { Termination } \\
\text { of pregnancy }\end{array}$ \\
\hline
\end{tabular}


Table 4 Forty five cases with inconsistent karyotyping and CNV-seq results (Continued)

\begin{tabular}{|c|c|c|c|c|c|}
\hline No. & $\begin{array}{l}\text { Indications for } \\
\text { prenatal diagnosis }\end{array}$ & $\begin{array}{l}\text { Abnormal } \\
\text { karyotypes }\end{array}$ & CNV-seq results & Fetal ultrasound & $\begin{array}{l}\text { Pregnancy } \\
\text { outcomes }\end{array}$ \\
\hline 27 & NIPT high-risk & $\begin{array}{l}47, X Y,+13[5] / 46 \\
X Y[63]\end{array}$ & CNVS- & Normal & $\begin{array}{l}\text { Gave birth to } \\
\text { a healthy boy }\end{array}$ \\
\hline 28 & $\begin{array}{l}\text { Advanced maternal } \\
\text { age }\end{array}$ & $\begin{array}{l}47, X Y,+18[5] / 46 \\
X Y[90]\end{array}$ & CNVs(-) & Polyhydramnios & $\begin{array}{l}\text { Gave birth to } \\
\text { a healthy boy }\end{array}$ \\
\hline 29 & NIPT high-risk & $47, \mathrm{XN},+\mathrm{mar}$ & $\begin{array}{l}\text { 12p12.1-p13.33 and 21q11.2- } \\
\text { q22.11duplication(pathogenic) }\end{array}$ & Normal & $\begin{array}{l}\text { Termination } \\
\text { of pregnancy }\end{array}$ \\
\hline 30 & $\begin{array}{l}\text { Maternal serum } \\
\text { screening high risk }\end{array}$ & $\begin{array}{l}\operatorname{mos} 46, X \\
+\operatorname{mar}[23] / 45, X \\
{[14]}\end{array}$ & $\begin{array}{l}\text { Xp11.21-p22.33 deletion } \\
\text { 56.8mb and Xq21.31-q28 } \\
\text { deletion } 64.6 \mathrm{mb} \text { (pathogenic) }\end{array}$ & $\begin{array}{l}\text { Short humerus and femoral length, Ventricular } \\
\text { Septal Defect }\end{array}$ & $\begin{array}{l}\text { Termination } \\
\text { of pregnancy }\end{array}$ \\
\hline 31 & $\begin{array}{l}\text { Advanced maternal } \\
\text { age }\end{array}$ & $47, \mathrm{XN},+\mathrm{mar}$ & 2q11.1-q11.2 duplication(VUS) & Bilateral choroid plexus cysts, enhanced bowel echo & $\begin{array}{l}\text { Lost to } \\
\text { follow-up }\end{array}$ \\
\hline 32 & $\begin{array}{l}\text { Advanced maternal } \\
\text { age }\end{array}$ & $47, X X,+$ mar & 5q21.2-q21.3 duplication, VUS & Normal & $\begin{array}{l}\text { Continue } \\
\text { pregnancy }\end{array}$ \\
\hline 33 & $\begin{array}{l}\text { Amniotic fluid } 46, \\
\text { XN[38] /47,XN, } \\
\text { +mar[22] }\end{array}$ & $\begin{array}{l}\text { Cord blood } 47, X X \\
+ \text { mar }[17] / 46, X X \\
{[17]}\end{array}$ & $\begin{array}{l}\text { dup(8q24.22)Likely benign } \\
\text { variation }\end{array}$ & Normal & $\begin{array}{l}\text { Continue } \\
\text { pregnancy }\end{array}$ \\
\hline 34 & $\begin{array}{l}\text { NIPT: abnormal } \\
\text { chromosome } 3 \\
\text { number }\end{array}$ & $47, X X,+$ mar & Likely benign variation & Short nasal bone & $\begin{array}{l}\text { Gave birth to } \\
\text { a healthy girl }\end{array}$ \\
\hline 35 & Fetal acromphalus & $\begin{array}{l}47, X Y,+\operatorname{mar}[11] / \\
46, X Y[31]\end{array}$ & Likely benign variation & Acromphalus, edema & $\begin{array}{l}\text { Termination } \\
\text { of pregnancy }\end{array}$ \\
\hline 36 & Thalassaemia? & $\begin{array}{l}47, X X,+\operatorname{mar}[13] / \\
46, X X[62]\end{array}$ & Likely benign variation & Normal & $\begin{array}{l}\text { Gave birth to } \\
\text { a healthy girl }\end{array}$ \\
\hline 37 & $\begin{array}{l}\text { Advanced maternal } \\
\text { age }\end{array}$ & $\begin{array}{l}47, X Y,+\operatorname{mar}[7] / 46, \\
X Y[33]\end{array}$ & Normal & Normal & $\begin{array}{l}\text { Gave birth to } \\
\text { a healthy boy }\end{array}$ \\
\hline 38 & NIPT high-risk & $\begin{array}{l}46, \mathrm{XN}, \mathrm{t}(1 ; 13)(\mathrm{q} 25 \\
\text { ?q22)de novo }\end{array}$ & $\begin{array}{l}\text { 13q14.3-q21.33 deletion } \\
23.1 \mathrm{mb} \text { (pathogenic) }\end{array}$ & Normal & $\begin{array}{l}\text { Termination } \\
\text { of pregnancy }\end{array}$ \\
\hline 39 & $\begin{array}{l}\text { Childbearing history } \\
\text { of deaf children }\end{array}$ & $\begin{array}{l}46, X Y \\
\text { dup(1)(q21.2)? }\end{array}$ & 1q521.2 duplication(VUS) & Normal & $\begin{array}{l}\text { Gave birth to } \\
\text { a healthy boy }\end{array}$ \\
\hline 40 & NIPT high-risk & $46, X, \operatorname{del}(Y)(q 11) ?$ & $\begin{array}{l}\text { Xp22.31-p22.33 duplication } \\
\text { VUS }\end{array}$ & $\begin{array}{l}\text { Fetal right ventricular wall has strong echo and was } \\
\text { thickened }\end{array}$ & $\begin{array}{l}\text { Lost to } \\
\text { follow-up }\end{array}$ \\
\hline 41 & NIPT high-risk & $\begin{array}{l}46, X N \\
\text { inv.(9)(p12q13)[79] }\end{array}$ & DS mosaic[20\%] & Normal & $\begin{array}{l}\text { Lost to } \\
\text { follow-up }\end{array}$ \\
\hline 42 & $\begin{array}{l}\text { Maternal serum } \\
\text { screening high risk, } \\
\text { Advanced maternal } \\
\text { age }\end{array}$ & $\begin{array}{l}\text { 45,X,der(13)t(Y; } \\
\text { 13)(q11.2?; } \\
\text { p10?)[26]/45,X [5] }\end{array}$ & $\mathrm{X}$,del(Y)[75\%]/XO[25\%] & FGR? & $\begin{array}{l}\text { Termination } \\
\text { of pregnancy }\end{array}$ \\
\hline 43 & $\begin{array}{l}\text { Maternal serum } \\
\text { screening high risk }\end{array}$ & $46, X Y[45]$ & $X Y[60 \%] / X Y Y[40 \%]$ & Right aortic arch & $\begin{array}{l}\text { Continue } \\
\text { pregnancy }\end{array}$ \\
\hline 44 & NIPT high-risk & $46, X X[40]$ & $\begin{array}{l}\text { XXY } \\
\text { Gene detection:SRY existed, } \\
\text { AZF all missing }\end{array}$ & Male genitalia & $\begin{array}{l}\text { Gave birth to } \\
\text { a healthy boy } \\
2 \text { years-old }\end{array}$ \\
\hline 45 & NIPT high-risk & $46, X Y[83]$ & $47, X N,+2[23 \%] / 46, X N[77 \%]$ & Normal & $\begin{array}{l}\text { Termination } \\
\text { of pregnancy }\end{array}$ \\
\hline
\end{tabular}

portion of sex chromosome abnormalities showed abnormal findings in maternal serum screening [13]. It is unknown whether maternal serum screening is abnormal for pathogenic CNV. The findings of this study indicated that maternal serum screening can detect $55.2 \%$ of fetal pathogenic chromosomal microdeletion/ duplication in fetuses with normal or abnormal karyotype. The intrauterine phenotype of fetuses with pathogenic microdeletion/ duplication lacks specificity, so prenatal ultrasound scanning is difficult to identify. In this study, fetuses with autosomal aneuploidy had the most severe ultrasound abnormalities, followed by pathogenic microdeletion/duplication with a large variability that some fetuses had completely normal ultrasonography. Fetuses with abnormal sex chromosome number and structure and the mosaic had mild ultrasound abnormalities. Fetal ultrasound scanning had higher sensitivity for autosomal aneuploidy. However, if other prenatal screening 
Table 5 Performances of karyotyping over CNV-seq in each indication for prenatal diagnosis

\begin{tabular}{|c|c|c|c|c|c|c|c|c|c|c|c|}
\hline \multirow{2}{*}{$\begin{array}{l}\text { Indication for prenatal } \\
\text { diagnosis } \\
\text { NIPT }\end{array}$} & \multicolumn{2}{|c|}{$\begin{array}{l}\text { P-del/dup }(n= \\
118)\end{array}$} & \multicolumn{2}{|c|}{ Auto A $(n=446)$} & \multicolumn{2}{|c|}{ Auto A M $(n=18)$} & \multicolumn{2}{|c|}{$\operatorname{Sex} A(n=156)$} & \multirow[t]{2}{*}{$\begin{array}{l}\text { Sex A M } \\
(n=33)\end{array}$} & \multirow[t]{2}{*}{$\begin{array}{l}\text { Total }(n= \\
771)\end{array}$} & \multirow[t]{2}{*}{$\begin{array}{l}P \\
\text { value }\end{array}$} \\
\hline & & & & & & & & & & & \\
\hline NIPT High-risk & \multicolumn{2}{|l|}{$30(25.40)$} & \multicolumn{2}{|c|}{$272(61.00)$} & \multicolumn{2}{|l|}{$11(61.00)$} & \multicolumn{2}{|c|}{$125(80.10)$} & $21(63.60)$ & $459(59.53)$ & \multirow{3}{*}{$\begin{array}{l}< \\
0.001\end{array}$} \\
\hline NIPT Low-risk & \multicolumn{2}{|l|}{$0(0.00)$} & \multicolumn{2}{|l|}{$0(0.00)$} & \multicolumn{2}{|l|}{$1(6.00)$} & \multicolumn{2}{|l|}{$0(0.00)$} & $0(0.00)$ & $1(0.13)$ & \\
\hline Absent & \multicolumn{2}{|l|}{$88(74.60)$} & \multicolumn{2}{|c|}{$174(39.00)$} & \multicolumn{2}{|l|}{$6(33.00)$} & \multicolumn{2}{|c|}{$31(19.90)$} & $12(36.40)$ & $311(40.34)$ & \\
\hline \multicolumn{12}{|l|}{ Maternal serum screening } \\
\hline $\begin{array}{l}\text { Maternal serum } \\
\text { screening High-risk }\end{array}$ & \multicolumn{2}{|l|}{$32(27.12)$} & \multicolumn{2}{|c|}{$129(28.90)$} & \multicolumn{2}{|l|}{$6(33.33)$} & \multicolumn{2}{|l|}{$8(5.10)$} & $13(39.40)$ & $188(24.40)$ & $\begin{array}{l}< \\
0.001\end{array}$ \\
\hline $\begin{array}{l}\text { Maternal serum } \\
\text { screening Low-risk }\end{array}$ & $26(22.03)$ & & $42(9.40)$ & & $4(22.22)$ & & $33(21.20$ & & $6(18.20)$ & $111(14.40)$ & \\
\hline Absent & $60(50.85)$ & & 275 & & $8(44.44)$ & & 115 & & $14(42.40)$ & $472(61.20)$ & \\
\hline fetal ultrasound & & & & & & & & & & & \\
\hline fetal ultrasound (0) & $47(39.83)$ & & $82(18.0$ & & $9(50.00)$ & & $88(56.41$ & & $13(39.40)$ & $239(31.00)$ & \\
\hline fetal ultrasound (1) & $20(16.95)$ & & $36(8.00)$ & & $5(28.00)$ & & $27(17.31$ & & $12(36.36)$ & $100(13.00)$ & \\
\hline fetal ultrasound (2) & $15(12.71)$ & & $177(40$. & & $1(5.50)$ & & $18(11.54$ & & $5(15.15)$ & $216(28.00)$ & \\
\hline fetal ultrasound (3) & $20(16.95)$ & & $78(18.0$ & & $2(11.00)$ & & $13(8.33)$ & & $2(6.06)$ & $115(14.90)$ & \\
\hline fetal ultrasound (4) & $16(13.56)$ & & $73(16.0$ & & $1(5.50)$ & & $10(6.41)$ & & $1(3.03)$ & $101(13.10)$ & \\
\hline maternal age & & & & & & & & & & & \\
\hline Advanced maternal age & $22(18.60)$ & & 210 & & $7(38.90)$ & & $49(31.40$ & & $12(36.40)$ & $300(38.90)$ & \\
\hline $\begin{array}{l}\text { maternal age }<35 \text { years } \\
\text { old }\end{array}$ & $96(81.40)$ & & $236(52$ & & $11(61.10)$ & & $107(68.6$ & & $21(63.60)$ & $471(61.10)$ & 001 \\
\hline $\begin{array}{l}\text { Indication for prenatal } \\
\text { diagnosis }\end{array}$ & $\begin{array}{l}\text { DS }(n= \\
358)\end{array}$ & $\begin{array}{l}\mathrm{ES}(n= \\
55)\end{array}$ & $\begin{array}{l}\text { PS }(n= \\
12)\end{array}$ & $\begin{array}{l}X X X \\
(n=28)\end{array}$ & $\begin{array}{l}X Y Y \\
(n=33)\end{array}$ & $\begin{array}{l}X X Y \\
(n=72)\end{array}$ & $\begin{array}{l}\mathrm{XO} \\
(n=13)\end{array}$ & $\begin{array}{l}\text { Triploid } \\
(n=2)\end{array}$ & $\begin{array}{l}\text { Unbalance } \\
(n=51)\end{array}$ & $\begin{array}{l}\text { Total }(n= \\
624)\end{array}$ & $\begin{array}{l}P \\
\text { value }\end{array}$ \\
\hline NIPT & & & & & & & & & & & \\
\hline NIPT High-risk & $\begin{array}{l}231 \\
(64.50)\end{array}$ & $\begin{array}{l}30 \\
(54.50)\end{array}$ & $\begin{array}{l}7 \\
(58.30)\end{array}$ & $\begin{array}{l}22 \\
(78.60)\end{array}$ & $\begin{array}{l}29 \\
(87.90)\end{array}$ & $\begin{array}{l}65 \\
(90.30)\end{array}$ & $\begin{array}{l}7 \\
(53.80)\end{array}$ & $0(0.00)$ & $16(31.40)$ & $407(65.20)$ & $\begin{array}{l}< \\
0.001\end{array}$ \\
\hline NIPT Low-risk & $0(0.00)$ & $0(0.00)$ & $0(0.00)$ & $0(0.00)$ & $0(0.00)$ & $0(0.00)$ & $0(0.00)$ & $1(50.00)$ & $0(0.00)$ & $1(0.20)$ & \\
\hline Absent & $\begin{array}{l}127 \\
(35.50)\end{array}$ & $\begin{array}{l}25 \\
(45.50)\end{array}$ & $\begin{array}{l}5 \\
(41.70)\end{array}$ & $6(21.40)$ & $4(12.10)$ & $7(9.70)$ & $\begin{array}{l}6 \\
(46.20)\end{array}$ & $1(50.00)$ & $35(68.60)$ & $216(34.60)$ & \\
\hline Maternal serum screening & & & & & & & & & & & \\
\hline $\begin{array}{l}\text { Maternal serum } \\
\text { screening High-risk }\end{array}$ & $\begin{array}{l}99 \\
(27.65)\end{array}$ & $\begin{array}{l}23 \\
(41.80)\end{array}$ & $\begin{array}{l}4 \\
(33.30)\end{array}$ & $0(0.00)$ & $2(6.06)$ & $3(4.20)$ & $\begin{array}{l}3 \\
(23.10)\end{array}$ & $1(50.00)$ & $8(15.70)$ & $143(22.90)$ & $\begin{array}{l}< \\
0.001\end{array}$ \\
\hline $\begin{array}{l}\text { Maternal serum } \\
\text { screening Low-risk }\end{array}$ & $\begin{array}{l}39 \\
(10.90)\end{array}$ & $0(0.00)$ & $\begin{array}{l}2 \\
(16.70)\end{array}$ & $8(28.60)$ & $6(18.18)$ & $\begin{array}{l}17 \\
(23.60)\end{array}$ & $1(7.70)$ & $0(0.00)$ & $11(21.60)$ & $84(13.50)$ & \\
\hline Absent & $\begin{array}{l}220 \\
(61.45)\end{array}$ & $\begin{array}{l}32 \\
(58.20)\end{array}$ & $\begin{array}{l}6 \\
(50.00)\end{array}$ & $\begin{array}{l}20 \\
(71.40)\end{array}$ & $\begin{array}{l}25 \\
(75.76)\end{array}$ & $\begin{array}{l}52 \\
(72.20)\end{array}$ & $\begin{array}{l}9 \\
(69.20)\end{array}$ & $1(50.00)$ & $32(62.70)$ & $397(63.60)$ & \\
\hline Fetal ultrasound & & & & & & & & & & & \\
\hline fetal ultrasound (0) & $\begin{array}{l}77 \\
(21.51)\end{array}$ & $3(5.45)$ & $1(8.30)$ & $\begin{array}{l}18 \\
(64.30)\end{array}$ & $\begin{array}{l}21 \\
(64.00)\end{array}$ & $\begin{array}{l}46 \\
(64.00)\end{array}$ & $1(8.00)$ & $0(0.00)$ & $17(33.33)$ & $184(29.00)$ & $\begin{array}{l}< \\
0.001\end{array}$ \\
\hline fetal ultrasound (1) & $31(8.66)$ & $5(9.09)$ & $0(0.00)$ & $6(21.40)$ & $4(12.00)$ & $\begin{array}{l}13 \\
(18.00)\end{array}$ & $\begin{array}{l}2 \\
(15.00)\end{array}$ & $0(0.00)$ & $5(9.80)$ & $66(11.00)$ & \\
\hline fetal ultrasound (2) & $\begin{array}{l}169 \\
(47.21)\end{array}$ & $4(7.27)$ & $0(0.00)$ & $1(3.60)$ & $4(12.00)$ & $\begin{array}{l}10 \\
(14.00)\end{array}$ & $\begin{array}{l}5 \\
(38.00)\end{array}$ & $0(0.00)$ & $9(17.65)$ & $202(32.00)$ & \\
\hline fetal ultrasound (3) & $\begin{array}{l}55 \\
(15.36)\end{array}$ & $\begin{array}{l}16 \\
(29.09)\end{array}$ & $\begin{array}{l}2 \\
(16.70)\end{array}$ & $2(7.10)$ & $4(12.00)$ & $2(3.00)$ & $1(8.00)$ & $0(0.00)$ & $11(21.57)$ & $93(15.00)$ & \\
\hline fetal ultrasound (4) & $26(7.26)$ & $\begin{array}{l}27 \\
(49.10)\end{array}$ & $\begin{array}{l}9 \\
(75.00)\end{array}$ & $1(3.60)$ & $0(0.00)$ & $1(1.00)$ & $\begin{array}{l}4 \\
(31.00)\end{array}$ & $2(100.00)$ & $9(17.65)$ & $79(13.00)$ & \\
\hline Maternal age & & & & & & & & & & & \\
\hline Advanced maternal age & $\begin{array}{l}179 \\
(50.00)\end{array}$ & $\begin{array}{l}23 \\
(41.80)\end{array}$ & $\begin{array}{l}3 \\
(25.00)\end{array}$ & $\begin{array}{l}14 \\
(50.00)\end{array}$ & $4(12.10)$ & $\begin{array}{l}27 \\
(37.50)\end{array}$ & $0(0.00)$ & $1(50.00)$ & $7(13.70)$ & $258(41.30)$ & $\begin{array}{l}< \\
0.001\end{array}$ \\
\hline
\end{tabular}


Table 5 Performances of karyotyping over CNV-seq in each indication for prenatal diagnosis (Continued)

\begin{tabular}{|c|c|c|c|c|c|c|c|c|c|c|c|}
\hline $\begin{array}{l}\text { Indication for prenatal } \\
\text { diagnosis }\end{array}$ & \multicolumn{2}{|c|}{$\begin{array}{l}\text { P-del/dup ( } n= \\
118)\end{array}$} & \multicolumn{2}{|c|}{ Auto A $(n=446)$} & \multicolumn{2}{|c|}{ Auto A M $(n=18)$} & \multicolumn{2}{|c|}{$\operatorname{Sex} A(n=156)$} & \multirow{2}{*}{$\begin{array}{l}\begin{array}{l}\text { Sex A M } \\
(n=33)\end{array} \\
44(86.30)\end{array}$} & \multirow{2}{*}{$\begin{array}{l}\text { Total }(\boldsymbol{n}= \\
\text { 771) } \\
366(58.70)\end{array}$} & $\begin{array}{l}P \\
\text { valu }\end{array}$ \\
\hline $\begin{array}{l}\text { unadvanced maternal } \\
\text { age }\end{array}$ & $\begin{array}{l}179 \\
(50.00)\end{array}$ & $\begin{array}{l}32 \\
(58.20)\end{array}$ & $\begin{array}{l}9 \\
(75.00)\end{array}$ & $\begin{array}{l}14 \\
(50.00)\end{array}$ & $\begin{array}{l}29 \\
(87.90)\end{array}$ & $\begin{array}{l}45 \\
(62.50)\end{array}$ & $\begin{array}{l}13 \\
(100.00)\end{array}$ & 0) & & & \\
\hline
\end{tabular}

$P$ values were the statistical difference of constituent ratios by Chi-square test between NIPT and CNV-seq, maternal serum screening and CNV-seq, fetal ultrasound and CNV-seq, maternal age and CNV-seq

Table 6 Cases with high risk of combined screening test but low risk NIPT

\begin{tabular}{|c|c|c|c|c|c|c|}
\hline & $\begin{array}{l}\text { Maternal } \\
\text { serum } \\
\text { screening }\end{array}$ & Fetal ultrasound & $\begin{array}{l}\text { Maternal } \\
\text { age (years) }\end{array}$ & $\begin{array}{l}\text { Fetal CNV-seq } \\
\text { results }\end{array}$ & Fetal karyotypes & $\begin{array}{l}\text { Pregnancy } \\
\text { outcomes }\end{array}$ \\
\hline 1 & N/A & $\begin{array}{l}\text { Ventriculomegaly, cardiac malformations, } \\
\text { pulmonary dysplasia }\end{array}$ & 28 & $\begin{array}{l}47, \mathrm{XN},+ \\
13[40 \%] / 46, \\
X N[60 \%]\end{array}$ & $47, X Y,+13[12] / 46, X Y[74]$ & $\begin{array}{l}\text { Termination of } \\
\text { pregnancy }\end{array}$ \\
\hline 2 & High risk & $\begin{array}{l}\text { Imbalance of head-body ratio, double outlet right } \\
\text { ventricle, absent left lung }\end{array}$ & 27 & Normal & $69, X X X$ & $\begin{array}{l}\text { Termination of } \\
\text { pregnancy }\end{array}$ \\
\hline 3 & Low risk & Nasal bone dysplasia & 30 & $\begin{array}{l}\text { Likely benign } \\
\text { variation }\end{array}$ & $46, X X, t(11 ; 17)(q 21 ; q 23)$ & $\begin{array}{l}\text { Continue } \\
\text { pregnancy }\end{array}$ \\
\hline 4 & N/A & Right aortic arch & 36 & $\begin{array}{l}\text { Likely benign } \\
\text { variation }\end{array}$ & $46, X N$,inv.(9)(p12q13) & $\begin{array}{l}\text { Continue } \\
\text { pregnancy }\end{array}$ \\
\hline 5 & Low risk & $\begin{array}{l}\text { Enhanced echo in both kidneys and intestine, } \\
\text { pleural effusion }\end{array}$ & 31 & $\begin{array}{l}\text { Likely benign } \\
\text { variation }\end{array}$ & $46, X X, t(12 ; 22)(q 24.1 ; q 13)$ & $\begin{array}{l}\text { Continue } \\
\text { pregnancy }\end{array}$ \\
\hline 6 & Threshold risk & Right choroid plexus cyst & 28 & $\begin{array}{l}\text { Likely benign } \\
\text { variation }\end{array}$ & $46, X Y, 1 \mathrm{qh}+$ & $\begin{array}{l}\text { Continue } \\
\text { pregnancy }\end{array}$ \\
\hline 7 & Low risk & Normal & 40 & Normal & $\begin{array}{l}46, X X \\
\text { inv.(19)(p13.3q13.1) }\end{array}$ & $\begin{array}{l}\text { Continue } \\
\text { pregnancy }\end{array}$ \\
\hline 8 & N/A & Normal & 36 & Normal & $\begin{array}{l}46, X Y, t(8 ; 16)(q 12 ; \\
q 21) m a t\end{array}$ & $\begin{array}{l}\text { Continue } \\
\text { pregnancy }\end{array}$ \\
\hline 9 & N/A & Duodenal atresia & 23 & Normal & $46, X X, t(2 ; 7)(q 13 ; q 22)$ & $\begin{array}{l}\text { Continue } \\
\text { pregnancy }\end{array}$ \\
\hline 10 & N/A & Nasal bone absent & 38 & Normal & $46, X Y, 15 \mathrm{ps}+$ & $\begin{array}{l}\text { Continue } \\
\text { pregnancy }\end{array}$ \\
\hline 11 & N/A & $\begin{array}{l}\text { Thickened ventricular wall, small heart size, } \\
\text { enlarged liver and spleen }\end{array}$ & 26 & Normal & $46, X Y, 21 \mathrm{ps}+$ & \\
\hline 12 & Low risk & $\begin{array}{l}\text { Holoprosencephaly, clearly displayed nasal bones, } \\
\text { incontinuity of upper alveolar process }\end{array}$ & 31 & Normal & $\begin{array}{l}\text { Chorionic villus } \\
\text { sampling, no } \\
\text { karyotyping }\end{array}$ & $\begin{array}{l}\text { Termination of } \\
\text { pregnancy }\end{array}$ \\
\hline 13 & N/A & Ventricular septal defect, hemivertebra, scoliosis & 26 & Normal & Normal & $\begin{array}{l}\text { Termination of } \\
\text { pregnancy }\end{array}$ \\
\hline 14 & N/A & $\begin{array}{l}\text { Holoprosencephaly, agenesis of corpus callosum, } \\
\text { hydrocephalus }\end{array}$ & 33 & Normal & Normal & $\begin{array}{l}\text { Termination of } \\
\text { pregnancy }\end{array}$ \\
\hline 15 & N/A & $\begin{array}{l}\text { Absent right lung, Tetralogy of Fallot, } \\
\text { hemivertebrae }\end{array}$ & 25 & Normal & Normal & $\begin{array}{l}\text { Termination of } \\
\text { pregnancy }\end{array}$ \\
\hline 16 & Threshold risk & Complete endocardial cushion defect & 25 & Normal & Normal & $\begin{array}{l}\text { Termination of } \\
\text { pregnancy }\end{array}$ \\
\hline 17 & N/A & Left ventricular rhabdomyomas, strephenopodia & 36 & Normal & Normal & $\begin{array}{l}\text { Termination of } \\
\text { pregnancy }\end{array}$ \\
\hline 18 & Low risk & Left microtia, nasal dysplasia, atresia of nostril & 35 & Normal & Normal & $\begin{array}{l}\text { Termination of } \\
\text { pregnancy }\end{array}$ \\
\hline 19 & N/A & $\begin{array}{l}\text { Ventricular septal defect, pulmonary artery stenosis, } \\
\text { missing pubic bones, hooked hands }\end{array}$ & 33 & Normal & Normal & $\begin{array}{l}\text { Termination of } \\
\text { pregnancy }\end{array}$ \\
\hline
\end{tabular}


Table 7 Predictive efficiencies of single indication for pathogenic fetal CNV-seq results

\begin{tabular}{|c|c|c|c|c|c|c|c|c|}
\hline & & \multicolumn{2}{|l|}{ CNV } & \multirow[t]{2}{*}{ Total } & \multirow{2}{*}{$\begin{array}{l}\text { McNemar's } \\
x^{2}\end{array}$} & \multirow[t]{2}{*}{$P$ value } & \multirow[t]{2}{*}{ Sensitivity } & \multirow[t]{2}{*}{ Specificity } \\
\hline & & 1 & 0 & & & & & \\
\hline \multirow[t]{2}{*}{ NIPT } & 1 & 459 & 339 & 798 & 334.03 & $<0.001$ & $1.00(0.99,1.00)$ & $0.22(0.18,0.26)$ \\
\hline & 0 & 1 & 96 & 97 & & & & \\
\hline Total & & 460 & 435 & 895 & & & & \\
\hline \multirow[t]{2}{*}{ Maternal serum screening } & 1 & 188 & 1517 & 1705 & 1212.5 & $<0.001$ & $0.63(0.57,0.68)$ & $0.37(0.35,0.39)$ \\
\hline & 0 & 111 & 884 & 995 & & & & \\
\hline Total & & 299 & 2401 & 2700 & & & & \\
\hline \multirow[t]{2}{*}{ fetal ultrasound } & 1 & 532 & 1585 & 2117 & 991.79 & $<0.001$ & $0.69(0.66,0.72)$ & $0.59(0.57,0.60)$ \\
\hline & 0 & 239 & 2245 & 2484 & & & & \\
\hline Total & & 771 & 3830 & 4601 & & & & \\
\hline \multirow[t]{2}{*}{ Advanced maternal age } & 1 & 300 & 1207 & 1507 & 321.95 & $<0.001$ & $0.39(0.35,0.42)$ & $0.68(0.67,0.70)$ \\
\hline & 0 & 471 & 2623 & 3094 & & & & \\
\hline Total & & 771 & 3830 & 4601 & & & & \\
\hline
\end{tabular}

CNV

1-including pathogenic microdeletion/duplication, Auto A, Sex A, Auto AM, Sex AM

0 -including likely pathogenic (LP-), uncertain significance (VUS-), likely benign (LB-) and benign (B-)

NIPT.

1-high risk.

0-low risk.

Maternal serum screening.

1-high risk.

0-low risk.

Fetal ultrasound

1-abnormal ultrasound findings (grades 2-4).

0-normal or subnormal ultrasound findings (grades $0-1$ ).

Advanced maternal age

1-Advanced maternal age ( $\geq 35 \mathrm{yrs}$ )

0 -Maternal age (<35 yrs).

methods such as NIPT and maternal serum screening are unavailable at the same time, the ultrasonologist's subjective assessments of fetal subtle facial features/ minor heart variations are inadequate for accurate assessment of fetal prognosis, and the clinical value is limited. NIPT has been widely used as a first-line prenatal screening method [14]. It was reported that the sensitivities of NIPT for Trisomy 21, 18, 13 are 99.1, 98.2 and $100 \%$, respectively [14]. The detection rates of NIPT for fetal aneuploidy and $\mathrm{CNV}>20 \mathrm{Mb}$ were

Table 8 Sensitivity and Specificity of single or multiple indications for fetal pathogenic CNV

\begin{tabular}{|c|c|c|c|c|c|c|c|c|}
\hline & & \multicolumn{2}{|l|}{ CNV } & \multirow[t]{2}{*}{ Total } & \multirow{2}{*}{$\begin{array}{l}\text { McNemar's } \\
x^{2}\end{array}$} & \multirow[t]{2}{*}{$P$ value } & \multirow[t]{2}{*}{ Sensitivity } & \multirow[t]{2}{*}{ Specificity } \\
\hline & & 1 & 0 & & & & & \\
\hline \multirow[t]{2}{*}{ Positive for single indication } & 1 & 746 & 3315 & 4061 & 3286.1 & $<0.001$ & $0.99(0.98,0.99)$ & $0.10(0.09,0.11)$ \\
\hline & 0 & 9 & 356 & 365 & & & & \\
\hline Total & & 755 & 3671 & 4426 & & & & \\
\hline \multirow[t]{2}{*}{ Positive for two indications } & 1 & 746 & 3315 & 4061 & 546.15 & $<0.001$ & $0.69(0.65,0.72)$ & $0.70(0.69,0.72)$ \\
\hline & 0 & 9 & 356 & 365 & & & & \\
\hline Total & & 755 & 3671 & 4426 & & & & \\
\hline \multirow[t]{2}{*}{ Positive for three indications } & 1 & 180 & 88 & 268 & 356.25 & $<0.001$ & $0.24(0.21,0.27)$ & $0.98(0.97,0.98)$ \\
\hline & 0 & 575 & 3583 & 4158 & & & & \\
\hline Total & & 755 & 3671 & 4426 & & & & \\
\hline \multirow[t]{2}{*}{ Positive for four indications } & 1 & 15 & 1 & 16 & 751.01 & $<0.001$ & $0.02(0.01,0.03)$ & $1.00(1.00,1.00)$ \\
\hline & 0 & 740 & 3670 & 4410 & & & & \\
\hline Total & & 755 & 3671 & 4426 & & & & \\
\hline
\end{tabular}


reported to be $100 \%$ [15]. NIPT was an effective method for prenatal screening of fetal $\mathrm{CNV}$ ranging from 1 to $129 \mathrm{Mb}$, with a sensitivity of $84.2 \%$ [16]. The findings of this study indicated that NIPT was a reliable method for prenatal screening of fetal pathogenic microdeletion/duplication. However, NIPT cannot detect fetal polymorphism, polyploids, balanced translocations and other fetal structural abnormalities. Therefore, the combination of maternal age, maternal serum screening, fetal ultrasound scanning and NIPT had been recommended for prenatal screening in some studies [17]. Our findings were partially in agreement with this perspective. For pathogenic $\mathrm{CNV}$, the sensitivity of single prenatal diagnosis indication was $0.99(0.98,0.99)$, but the specificity was $0.10(0.09,0.11)$. When prenatal diagnosis indications increased from two to four, the sensitivity was decreased to $0.02(0.01-0.03)$ and the specificity increased to $1.00(1.00-1.00)$. According to our data, the combination of two screening method was possibly to achieve a maximal summation of sensitivity and specificity. Moreover, each combined screening program had its own advantages and limitations, which require comprehensive consideration by the couples and doctors.

In short, we would recommend that combined at least two kinds of prenatal screening could be used as the efficient program if medical resources for prenatal care are sufficient and the couples are willing to receive the screening.

\section{Conclusions}

Combination of cytogenetic karyotyping and CNV-Seq significantly improves the detection rate of fetal pathogenic chromosome microdeletion/duplication. NIPT was recommended for the screening of pathogenic chromosome microdeletion/duplication, and NIPT combining with other screening methods further improved the screening performance for pathogenic fetal CNV.

\footnotetext{
Abbreviations

ACMG: American college of medical genetics and genomics; AMP: Association for molecular pathology; Auto A: Autosome aneuploidy; Auto AM: autosome aneuploidy mosaic; B-CNV: benign copy number variations; CAP: College of american pathologists; CMA: Chromosome microarray analysis; CNV: Copy number variation; CNV-Seq: Copy number variation-sequencing;: DS: Down's syndrome, trisomy 21 syndrome; ES: Edward's syndrome, trisomy 18 syndrome; FGR: Fetal growth restriction; ISCN: International system for human cytogenetic nomenclature; LBCNV: Likely benign copy number variations; LP-CNV: Likely pathogenic copy number variations; NF: Nuchal fold; NIPT: Noninvasive prenatal testing; NT: Nuchal translucency; P-CNV: Pathogenic copy number variations; PS: Patau 's syndrome, trisomy 13 syndrome; Sex A: abnormal sex chromosome number; Sex AM: abnormal sex chromosome number mosaic. VUS- CNV: copy number variations of uncertain significance
}

\section{Authors' contributions}

Jinman Zhang has participated in the design and performance of the work, analysis of data and drafted the manuscript; Xinhua Tang, Jilin Hu, Guilin He and Jian Wang have participated in the performance of the work, analysis of data; Baosheng Zhu and Yingting Zhu have directed the design of the work, analysis of data and substantively revised this manuscript. Baosheng Zhu have also obtained funds to support this designated work. The author(s) read and approved the final manuscript.

\section{Funding}

1 Major Scientific and Technological Project of Yunnan Province: Yunnan Provincial Clinical Research Center for Birth Defects and Rare Diseases (Grant Number: 2019ZF015, 201901-202012).

2 Yunnan Provincial Medical Leading Scholar Program - Obstetrics by the Health Department of Yunnan Province (Grant Number: D-2018055, 202001202212)

3. Research on the Key Technologies of Applicable Clinical Medicine in Yunnan Province: Research on Key Technologies of Screening and Intervention for Maternal and Child Health in Elderly or Re-procreating Families. (Grant Number: 2018ZF009, 201801-202012).

\section{Availability of data and materials}

The datasets from the current study are available from the corresponding author upon request.

\section{Declarations}

Ethics approval and consent to participate

The proposal of this study was approved by the Ethics Committee of Institutional Research Board (IRB), First People's Hospital of Yunnan Province, China (Committee reference number, KHLL2020-KY025). All study patients provided written informed consent, in the First People's Hospital of Yunnan Province, China.

\section{Consent for publication}

All authors have agreed to submit this manuscript to your journal for consideration of publication. In addition, consent for publication from all individuals (in the case of children, their parents or legal guardians) involved in this study, including any individual person's data in any form, such as any individual details, images or videos, has been obtained in written forms, available upon request.

\section{Competing interests}

No competing interests are declared from all authors.

\section{Author details}

${ }^{1}$ Faculty of Environmental Science and Engineering, Kunming University of Science and Technology, Kunming, Yunnan 650500, People's Republic of China. ${ }^{2}$ Department of Obstetrics and Gynecology, First People's Hospital of Yunnan Province, No. 157, Jinbi Road, Xishan District, Kunming, Yunnan 650032, People's Republic of China. 3Shanghai Children's Medical Center, Shanghai 200127, People's Republic of China. ${ }^{4}$ Research and Development Department, TissueTech, Inc., 7235 Corporate Center Drive, Suite B, Miami, Florida 33126, USA.

Received: 19 November 2020 Accepted: 28 May 2021

Published online: 08 July 2021

\section{References}

1. Mak ASL, Ma TWL, Chan KYK, Kan ASY, Tang MHY, Leung KY. Prenatal diagnosis of $5 p$ deletion syndrome: report of five cases. J Obstet Gynaecol Res. 2019;45(4):923-6. https://doi.org/10.1111/jog.13911.

2. Xing Y, Holder JL Jr, Liu Y, Yuan M, Sun Q, Qu X, et al. Prenatal diagnosis of wolf-Hirschhorn syndrome: from ultrasound findings, diagnostic technology to genetic counseling. Arch Gynecol Obstet. 2018;298(2):289-95. https://doi. org/10.1007/s00404-018-4798-1.

3. Chen CP, Ko TM, Wang LK, Chern SR, Wu PS, Chen SW, et al. Prenatal diagnosis of a 0.7-Mb 17p13.3 microdeletion encompassing YWHAE and CRK but not PAFAH1B1 in a fetus without ultrasound abnormalities. Taiwan J Obstet Gynecol. 2018;57(1):128-32. https://doi.org/10.1016/j.tjog.2017.12. 022. 
4. Yuan $M$, Deng L, Yang Y, Sun L. Intrauterine phenotype features of fetuses with Williams-Beuren syndrome and literature review. Ann Hum Genet. 2020;84(2):169-76. https://doi.org/10.1111/ahg.12360.

5. Chen CP, Chang SY, Wang LK, Chang TY, Chern SR, Wu PS, et al. Prenatal diagnosis of a familial 15q11.2 (BP1-BP2) microdeletion encompassing TUBGCP5, CYFIP1, NIPA2 and NIPA1 in a fetus with ventriculomegaly, microcephaly and intrauterine growth restriction on prenatal ultrasound. Taiwan J Obstet Gynecol. 2018;57(5):730-3. https://doi.org/10.1016/j.tjog.201 8.08.022.

6. Zhang X, He P, Han J, Pan M, Yang X, Zhen L, et al. Prenatal detection of 1 p36 deletion syndrome: ultrasound findings and microarray testing results. J Matern Fetal Neonatal Med. 2019:1-121.

7. Miller DT, Adam MP, Aradhya S, Biesecker LG, Brothman AR, Carter NP, et al. Consensus statement: chromosomal microarray is a first-tier clinical diagnostic test for individuals with developmental disabilities or congenital anomalies. Am J Hum Genet. 2010;86(5):749-64. https://doi.org/10.1016/j.a jhg.2010.04.006

8. Wang J, Chen L, Zhou C, Wang L, Xie H, Xiao Y, et al. Identification of copy number variations among fetuses with ultrasound soft markers using nextgeneration sequencing. Sci Rep. 2018;8(1):8134. https://doi.org/10.1038/s41 598-018-26555-6.

9. Simons A, Shaffer LG, Hastings RJ. Cytogenetic nomenclature: changes in the ISCN 2013 compared to the 2009 edition. Cytogenet Genome Res. 2013; 141(1):1-6. https://doi.org/10.1159/000353118.

10. Brothman AR, Persons DL, Shaffer LG. Nomenclature evolution: changes in the ISCN from the 2005 to the 2009 edition. Cytogenet Genome Res. 2009; 127(1):1-4. https://doi.org/10.1159/000279442.

11. Richards S, Aziz N, Bale S, Bick D, Das S, Gastier-Foster J, et al. Standards and guidelines for the interpretation of sequence variants: a joint consensus recommendation of the American College of Medical Genetics and Genomics and the Association for Molecular Pathology. Genet Med. 2015; 17(5):405-24. https://doi.org/10.1038/gim.2015.30.

12. Carlson LM, Vora NL. Prenatal diagnosis: screening and diagnostic tools. Obstet Gynecol Clin N Am. 2017:44(2):245-56. https://doi.org/10.1016/j.ogc.2 017.02.004.

13. Viuff MH, Stochholm K, Uldbjerg N, Nielsen BB, Danish fetal medicine study G, Gravholt CH. Only a minority of sex chromosome abnormalities are detected by a national prenatal screening program for Down syndrome. Hum Reprod. 2015;30(10):2419-26. https://doi.org/10.1093/humrep/dev192.

14. Zhang H, Gao Y, Jiang F, Fu M, Yuan Y, Guo Y, et al. Non-invasive prenatal testing for trisomies 21, 18 and 13: clinical experience from 146,958 pregnancies. Ultrasound Obstet Gynecol. 2015;45(5):530-8. https://doi.org/1 0.1002/uog.14792.

15. Luo Y, Jia B, Yan K, Liu S, Song X, Chen M, et al. Pilot study of a novel multifunctional noninvasive prenatal test on fetus aneuploidy, copy number variation, and single-gene disorder screening. Mol Genet Genomic Med. 2019;7(4):e00597. https://doi.org/10.1002/mgg3.597.

16. Liu H, Gao Y, Hu Z, Lin L, Yin X, Wang J, et al. Performance evaluation of NIPT in detection of chromosomal copy number variants using lowcoverage whole-genome sequencing of plasma DNA. PLoS One. 2016;11(7): e0159233. https://doi.org/10.1371/journal.pone.0159233.

17. Suciu I, Galeva S, Abdel Azim S, Pop L, Toader O. First-trimester screeningbiomarkers and cell-free DNA. J Matern Fetal Neonatal Med. 2019:1-7. https://doi.org/10.1080/14767058.2019.1698031.

\section{Publisher's Note}

Springer Nature remains neutral with regard to jurisdictional claims in published maps and institutional affiliations.

Ready to submit your research? Choose BMC and benefit from:
- fast, convenient online submission
- thorough peer review by experienced researchers in your field
- rapid publication on acceptance
- support for research data, including large and complex data types
- gold Open Access which fosters wider collaboration and increased citations
- maximum visibility for your research: over 100M website views per year
At BMC, research is always in progress.
Learn more biomedcentral.com/submissions

